\title{
A MODEL OF EARLY DETECTION AND DIAGNOSIS OF AUTISM SPECTRUM DISORDER
}

\author{
AlSayed Mohamed AbdElAzim \\ Department of Computer and Information Systems, Faculty of Engineering, Al Azhar University
}

\begin{abstract}
Autism and autism spectrum disorder (ASD) are a group of severe developmental disorders that are characterized by 3 core sets of developmental abnormalities: impairment of social interaction, verbal and nonverbal communication, and restricted, repetitive patterns of behavior. The disorder is far more common than previously thought. There is no cure for autism but it is apparent that early detection followed by early intervention is likely to provide the best chance of long-term beneficial outcome in this condition. Unfortunately, until recently, there had been no validated method of comprehensive early detection of ASD, nor a tool with adequate sensitivity and specificity to be recommended for universal screening of preschool children with ASD. We describe a model of comprehensive early detection and diagnosis of ASD that is achieved by using the resources of primary care workers and a multidisciplinary team with skill and experience in assessing developmental problems in young children and specific expertise in ASD. Both early detection and diagnosis may be carried out by this team in collaboration with parents and primary care professionals and can result in high rates of detection and diagnosis of ASD.
\end{abstract}

\section{INTRODUCTION}

THERE is general agreement that early detection and early intervention in disease or disability are essential for the long-term benefit of the child and family and also, in the long run, of society [1], [2], [3]. Parents want to be told at the earliest possible opportunity if there is any concern about their child's development or well-being [4]. This allows intervention services to be delivered to the child and support provided for the family. Parents are empowered to become knowledgeable about the nature and source of their child's difficulties and plans can be made for appropriate educational intervention for the child. It also enables the family to plan ahead for their future, especially in conditions that have genetic implications. Beside this, it is likely that the window of opportunity to bring about beneficial changes in at least some domains of children's development may be time sensitive [7]. For all these reasons, there is increasing emphasis on early identification of developmental problems and institution of appropriate early intervention to maximize the life chances of the child and the family.

Autism and ASD, also known as pervasive developmental disorder (PDD), are a group of severe developmental disorders that are characterized by 3 core sets of developmental abnormalities: impairment of social interaction and communication, and restricted and repetitive patterns of behavior and interest [8]. The developmental abnormalities manifest themselves early in infancy and may be present from birth. Autism is the most well defined and most intensively researched of all childhood developmental disorders. It is also not as uncommon as was previously thought [9]. Current best estimates of the prevalence of ASD in children under the age of 8 years is of the order of 1 per 68 children [10]. Autism spectrum disorder can occur in children at all levels of 
intelligence. However, irrespective of the associated intellectual level, nearly all children with ASD have significant long-term disability. The cause or causes of autism are not known but it is recognized that there is a strong genetic component toward the liability to develop ASD [11]. Parents who has a child with abnormal development, impairment of social interaction and communication, often does not perform an examination of the child, we do not have the culture of early detection of children and often leave them over time will improve.

Detection and Diagnosis MODEL

There is increasing recognition that early detection followed by early intervention targeting the core developmental deficits is likely to provide the best chance of long-term beneficial outcome for these children [12], [5], [13]. There is therefore an urgency to develop tools and methodologies for early detection and diagnosis of ASD.

Previous important instruments for screening/diagnosis of autism and ASD are Behavior Rating Instrument for Autistic and Atypical Children [15], Handicap, Behavior and Skills schedule [16], the Behavior Observation Scale [17], as well as the Autism Behavior Checklist [18] and the highly influential Childhood Autism Rating Scale [19].

Of the newer diagnostic instruments that conform to the current ICD-10 [20] and [21] diagnostic criteria of autism and ASD (PDD), the most important instruments are the Autism Diagnostic Interview - Revised [22], Autism Diagnostic Observation Schedule Generic [23], and the Diagnostic Interview for Social and Communication Disorders [24]. The screening instruments for use specifically for very young children are CHAT (Checklist for Autism in Toddlers) [25], Pervasive Developmental Disorder Screening Test (PDDST) [26], Screening Tool for Autism in Two-year-old (STAT) [27], and the Modified CHAT (M-CHAT) [28]. Of these screening tools, CHAT is the most rigorously researched and validated tool for use in very young children. CHAT is designed to screen for autism in children at 18 months of age and was originally used for screening a normal population of 16,235 children. CHAT consists of 2 parts, a parent questionnaire consisting of 9 items and a child practitioner observation schedule consisting of 5 items. Initial research showed CHAT to have very high specificity in identifying cases of autism among young children but subsequent follow-up study has shown that CHAT has poorer sensitivity in identifying less severe cases of ASD [29].

Researchers have devised a modified version of CHAT designated M-CHAT. M-CHAT consists of a 23-item parent questionnaire, which incorporates the original 9 items of the CHAT parent questionnaire as well as additional items. The questionnaire takes about 10 minutes to complete and is used purely as a screening instrument and not for diagnosis. Initial results of study using M-CHAT shows excellent sensitivity and specificity [28].

Our model as shown in (Figure 1),

Stage 1: The screening and surveillance program is carried out by health visitors, general practitioners (family physicians), and pediatricians, the program of surveillance and screening begins with the neonatal examination, followed by periodic assessments at 6 to 8 weeks, 6 to 9 months, 18 to 24 months, and at 3.25 to 3.5 years.

Stage 2: All parents along with their children referred at this initial stage were invited to a brief meeting lasting about half an hour with a child development team. The team consisted of a pediatrician, a health visitor, speech and language therapist, physical, occupational, and play therapist. During the meeting, there was opportunity to observe the child informally in brief play, encouraged by the play therapist, whereas the team explored the parents' and the referrer's concerns about the strengths and weaknesses of the child s development.

Stage 3: The children who were selected for in depth assessment attended the local child development center in groups of 4 children for a period of 2 weeks. The composition of each group remained constant during the assessment period and groups of 4 children were assessed 
consecutively at 2-week intervals. The assessments were conducted by a multidisciplinary team of professionals and spread over 10 daily sessions of 2 hours each. During the assessment, professionals use interactive multimedia system prepared to check the skills that are related to child age for example (color, classification, sorting, size and else), and a play therapist led the group of 4 children with their participating parents in structured activities as well as in free play in a specifically built nursery environment. Parents were invited to be with their children during these sessions.

Stage 4: Children who were strongly suspected to have ASD underwent further assessment with a standardized diagnostic measure, the Autism Diagnostic Interview-Revised (ADI-R), and a psychometric assessment, using the Wechsler Preschool and Primary Scale of Intelligence [32] or Merrill Palmer Scale [33]. Scales of Intelligence like (Wechsler, Palmer and Stanford binet), are made using Interactive multimedia system to get an accurate degree of intelligence for a child.

\section{RESULT \& DISCUSSION}

Detailed results and their likely interpretation are available in [34]. In brief, of the 576 children referred to the Child Development Center following stage 1 assessment, 97 children were diagnosed with PDD (ASD) at the completion of stage 4, resulting in a prevalence estimate of 62.6 (95\% CI, 50.8-76.3) per 10,000 children for all PDDs (ASDs). Of the 97 children, 26 were diagnosed with autistic disorder (16.8 per 10,000), 13 with Asperger syndrome (8.4 per 10000), 1 girl with Rett syndrome, 1 boy with childhood disintegrative disorder, and 56 children with PDDNOS (36.1 per 10000). Of the 97 children with PDD, 34\% of the children were referred by pediatricians, $32.9 \%$ by speech and language therapists, $21.6 \%$ by health visitors, and $5.1 \%$ by family physicians, and $6.2 \%$ were from various other sources. However, closer inspection of the referral pattern showed that most of the referrals to pediatricians and speech therapists were initiated by health visitors. Taking these data into account, it was estimated that $79(81 \%)$ of the 97 children were originally identified by health visitors as children with a developmental problem requiring further assessment.

\section{CONCLUSION}

In this article, we have described a model of detection and diagnosis of autism and ASD in young children (children between 2 and 4 years of age) by professional team and Interactive multimedia system. The model we have described is broadly in line with the main recommendation of the consensus panel [30] on screening and diagnosis of autism except the use of an autism-specific screening instrument.

Understandably, the common target of all ASD screening instruments is the identification of autism-specific behaviors and developmental patterns in children. Although there is extensive information and broad agreement about the presentation, range of behavior, and developmental patterns of children with autism, there is much less research and information about the antecedents of children with eventual diagnosis of milder variants of ASD such as PDDNOS (pervasive developmental disorder not otherwise specified) or Asperger syndrome. Because of this, we felt that it is important not to assume that these children with ASDs, but not autism disorders, would also present with behavioral features that have been commonly targeted in autism screening instruments. On the contrary, our view is that it is important to keep a broader perspective and target any atypical development in children as subjects of interest.

This article is part of thesis (Interactive Multimedia System to treat Children with Autism) 


\section{Stage 1}

Universal Screening/surveillance of young children

Birth, 6-8 weeks, 6-9 months, 18-24 months, 3.25-3.5 years

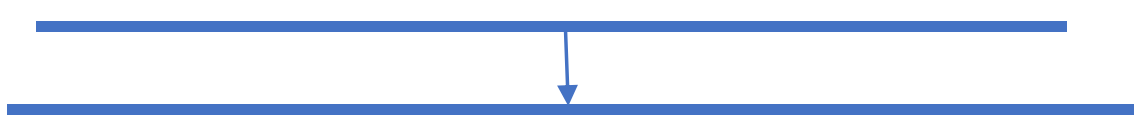

CHILDREN IDENTIFIED WITH A DEVELOPMENTAL PROBLEM

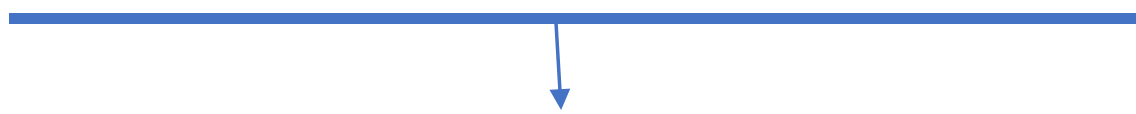

Stage 2

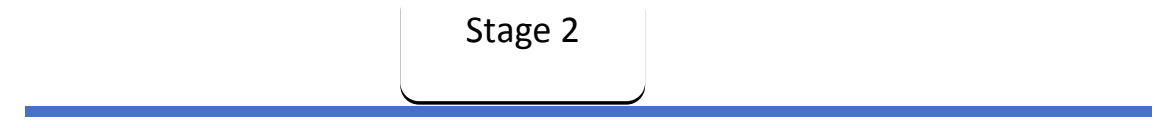

Assessment by Child Development Team (CDT)

(Observation of child and elicitation of development concerns

from parents and referrer)

\section{Mild Problem}

NO EXTRA SERVICES NEEDED BUT PROGRESS MONITORED BY CDT OR REFERRE

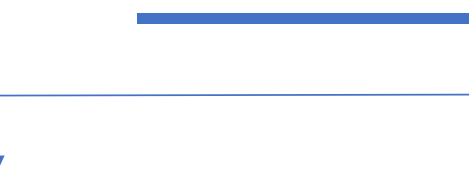

\section{Moderate Problem}

SPECIFIC DEVELOPMENTAL SERVICES OFFERED, E.G. SPEECH THERAPY, EARLY EDUCATIONAL INTERVENTION, Stage 3 PROGRESS MONITORED BY CDT

\section{Severe or complex Problem}

MULTIDISCIPLINARY ASSESSMENT: CLINICAL DIAGNOSIS OF ASD

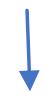

Stage 4

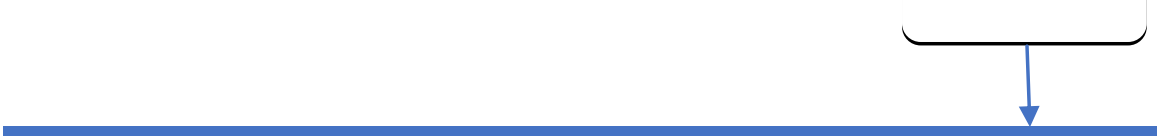

$A D I-R$ \& psychometric assessment of children with clinical diagnosis of ASD

Figure 1. Model of screening and diagnosis of ASD in preschool children. 
A MODEL OF EARLY DETECTION AND DIAGNOSIS OF AUTISM SPECTRUM DISORDER

\section{REFERENCES}

[1] Guralnick, M. J. (Ed.). (1997). The effectiveness of early intervention: Second generation research.

Baltimore:

Paul

$\mathrm{H}$.

Brookes

[2] Keating, D. P, \& Hertzman, C. (1999). Developmental health and the wealth of nations: Social, biological and educational dynamics. New York: The Guilford Press. [3] Shonkoff, J. P, \& Meisels, S. J. (2000). Handbook of early childhood intervention (2nd ed.). New York: Cambridge University Press. [4] Cunningham, C. C, Morgan, P A., \& McGucken, R. B. (1984). Down's syndrome: Is dissatisfaction with disclosure of diagnosis inevitable. Developmental Medicine \& Child Neurology, 26 ,

33-39. [5] McEachin,J. J., Smith, T., \&Lovaas, I. O. (1993). Long-term outcome for children with autism who received early intensive behavioral treatment. American Journal of Mental Retardation, 97 ,

359-372.

[6] Quine, L., \& Pahl, J. (1987). First diagnosis of severe mental handicap: A study of parental reactions. Developmental Medicine and Child Neurology, 29, 232-242. [7] Nelson, C. A. (2000). The neurobiological bases of early intervention. In Shonkoff \& Meisels (Eds.), Handbook of early childhood intervention (2nd ed., pp. 204-230). Cambridge, MA: Cambridge University

Press.

[8] American Psychiatric Association. (1994). Diagnostic and statistical manual oftnentai disorders (4th ed.). Washington, DC: Author. [9] Wing, L, \& Potter, D. (2002). The epidemiology of autistic spectrum disorders: Is the prevalence rising? Mental Retardation \& Developmental Disabilities Research Reviews, 8O), 151-161,

[10] Centers for Disease Control and Prevention http://www.cdc.gov/ncbddd/autism/data.html. [11] Rutter, M., Silberg, J., O'Connor, T, \& Simonoff, E. (1999). Genetics and child psychiatry: II. Empirical research findings. Journal of Child Psychology and Psychiatry, 40, 19-55. [12] Hoyson, M., Jamieson, B., \& Strain, P S. (1984). Individualized group instruction of normally developing and autistic-like children: The LEAP curriculum model. Journal ofthe $\begin{array}{llllll}\text { Division of } & \text { Early } & \text { Childhood, } & \text { 8, } & 157- & 72 .\end{array}$ [13] Rogers, S. J., \& Lewis, H. (1989). An effective day treatment model for young children with pervasive developmental disorders. Journal of the American Academy of Child and Adolescent Psychiatry,28,207-214.

[14] Rimland, B. (1968). On the objective diagnosis of infantile autism. Acta Paedo psychiatric, 35 , 146-161.

[15] Ruttenberg, B. A., Dratman, R., Frakner, T. A., \& Wenar, C. (1966). An instrument for evaluating autistic children. Journal ofthe American Academy of Child Psychiatry, 5, 453-478. [16] Wing, L, \& Gould, J, (1978). Systematic recording of behaviours and skills of retarded and psychotic children. Joumal of Autism and Childhood Schizophrenia, 8, 79-97.

[17] Freeman, B. J., Ritvo, E. R., Guthrie, D., Schroth, P, «\& Ball, J. (1978). The Behaviour Observation cale for autism: Initial methodology, data analysis and preliminary findings on 89 children ./ouma/ of the American Academy of Child Psychiatry, 17, 576-588. [18] Krug, D. A., Arick, J., \& Almond, P (1980). Behaviour checklist for identifying severely handicapped individuals with high levels of autistic behaviour./oMm «/ of Child Psychology and Psychiatry, 21, 221-229. [19] Schopler, E., Reichler, R. j. , \& Renner, B. R. (1988). The Childhood Autism Rating Scale (CARS). Los Angeles: Western Psychological Services. [20] World Health Organization, (1992). The ICD-IO classification of mental and behavioural disorders: Clinical descriptions and diagnostic guidelines. Geneva: Author, [21] American Psychiatric Association. (1994). Diagnostic and statisticai manuai oftnentai disorders (4th ed.). Washington, DC: [22] Lord, C, Rutter, M., \& Le Couter, A. (1994). Autism Diagnostic Interview-Revised: A revised version of a diagnostic interview for caregivers of individuals with possible pervasive developmental disorders. Journal of Autism and Developmental Disorders, 24, 659-685. 
[23] Lord, C, Risi, S., Lambrecht, L., Cook, E. H., and others (2000). The Autism Diagnostic Observation Schedule-Generic: A standard measure of social and communication deficits associated with the spectrum of autism./oMma/ of Autism and Developmental Disorders, 30, 205-223.

[24] Wing, L, Leekam, S. R, Iibby, S.J,, Gould,J., \& Larcombe, M. (2002). The diagnostic interview for social and communication disorders: Background, inter-rater reliability and clinical use. Joumal of Child Psychology and Psychiatry, 43, 307-325,

[25] Baron-Cohen, S., Allen, J., \& Gillberg, C. (1992). Can autism be detected at 18 months? The needle, the haystack and the CHAT. British Journal of Psychiatry, 161, 839-843. [26] Seigel, B. (1998). Early screening and diagnosis in autism spectrum disorders: The Pervasive Developmental Disorder Screening Test (PDDST). Paper presented at the NIH State of the Science in Autism Screening and Diagnosis Working Conference, Bethesda, MD [27] Stone, W, L, Coonrod, E, E, \& Ousley, O, Y. (2000). Brief report: Screening Tool for Autism in Two-year-olds (STAT): Development and preliminary data, joumal of Autism and Developmental Disorders, 30 607-612,

[28] Robins, D. L, Fein, D., Barton, M. L., \& Green, J. (2001). The Modified Checklist for Autism in Toddlers: An initial study investigating the early detection of autism and pervasive developmental disorders. Journal of Autism and Developmental Disorders, 31, 131-144. [29] Baird, G., Charman, T, Baron-Cohen, S., Cox, A., Sweetenham, J., Wheelwright, S., et al. (2000). A screening instrument for autism at 18 months of age: A 6-year follow-up study. Journal of the American Academy of Child and Adolescent Psychiatry, 39, 694-702 [30] Filipek, P A., Accardo, P J., Baranek, G. T, Cook, E. H., Jr., Dawson, G., Gordon, B., et al. (1999). The screening and diagnosis of autistic spectrum disorders. Journal of Autism and Developmental Disorders, 29, 439484 [31] Watson, L, R, Baranek, G. T, \& Di Lavore, P. C. (2003). Toddlers with autism, developmental perspectives. Infants and Young Children, 16, 201-21 [32] Wechsler, D. (1990). Manual for Wechsler preschool and primary scale of intelligenceRevised (British Amendments). Kent, England: The Psychological Corporation [33] Stutsman, R. 0948\}. Merrill Palmer Scale of Mental Tests (Preprints of Part III, Mental Measurement of Preschool Children). Chicago: Stoelting. [34] Fombonne, E. (2003). The prevalence of autism [Editorial].yAM4, 259(1), 87-89. 